\title{
Effects of Exogenous Melatonin on Photosynthetic Characteristics of Chinese Cabbage Seedlings under Aluminum Stress
}

\author{
Yi Tang ${ }^{1, a}$, Jingxian $\mathrm{Li}^{2, \mathrm{~b}}$, Enze Zhang ${ }^{2, \mathrm{c}}$ and Huanxiu $\mathrm{Li}^{1, \mathrm{~d}^{*}}$ \\ ${ }^{1}$ Institute of Pomology and Olericulture, Sichuan Agricultural University, Chengdu, Sichuan, China \\ ${ }^{2}$ College of Horticulture, Sichuan Agricultural University, Chengdu, Sichuan, China \\ atangyisunguochao@sina.com, bjxzbli@163.com, ${ }^{c} 570081509 @ q q . c o m,{ }^{d} h x l i 62 @ 163 . c o m$ \\ *Corresponding author
}

Keywords: Exogenous melatonin; Chinese cabbage; Aluminum stress

Abstract. A pot experiment was conducted to study the effects of exogenous melatonin (MT) on photosynthetic characteristics of Chinese cabbage under aluminum (Al) stress. Five treatments were used in the experiment: leaves were sprayed with $0(\mathrm{CK}), 50,100,200$ and $400 \mu \mathrm{mol} \cdot \mathrm{L}^{-1}$ concentrations of melatonin solution. The results showed that melatonin enhanced net photosynthetic rate $(\mathrm{Pn})$ and transpiration rate $(\mathrm{Tr})$ of Chinese cabbage significantly. With the increasing of melatonin concentration, photosynthetic capacities of Chinese cabbage seedlings were enhanced. The result of light use efficiency (LUE), water use efficiency (WUE) and stomatal conductance (Gs) were the same as $\mathrm{Pn}$. Spraying different concentrations of melatonin on Chinese cabbage under aluminum stress has not significant effect on $\mathrm{CO}_{2}$ concentration of intercellular $(\mathrm{Ci})$. Therefore, melatonin could use to enhance the photosynthetic ability of Chinese cabbage, which would help to improve the adaptability of Chinese cabbage, and the best concentration of melatonin was $200 \mu \mathrm{mol} \cdot \mathrm{L}^{-1}$.

\section{Introduction}

Chinese cabbage (Brassica rapa ssp. pekinensis) is an important vegetable, which is rich in nutrients. In China, Chinese cabbage cultivation area and consumption ranks first in all kinds of vegetables [1].

At present, China accounts for $21 \%$ of the acid soils of the total area. Aluminum toxicity in acidic soils is a major obstacle restricting vegetable production [2]. It was found that aluminum stress inhibited photosynthesis in soybean and longan $[3,4]$. Studies have shown that exogenous organic acids can effectively relieve aluminum toxicity of rapeseed and soybean[5,6], and exogenous $\mathrm{Ca}^{2+}$ can reduce aluminum toxicity on rye [7]. Exogenously added IAA can effectively alleviate the toxic effects of aluminum on roots of black soybean [8].

Melatonin (MT) is widely present in higher plants, which plays an important role in variety of physiological activities of plants[9,10]. In recent years, many studies have found that melatonin can alleviate abiotic stress harm to the plant, improve the resistance to low temperature and high temperature, maintain higher chlorophyll content and enhance the photosynthetic efficiency of leaves[11-12].

In this study, we used different concentrations of melatonin to spray Chinese cabbage seedlings for the purpose of screening the influence of melatonin on photosynthetic characteristics of Chinese cabbage under aluminum stress.

\section{Materials and Methods}

Materials. The experiments were conducted at Sichuan Agricultural University $\left(30^{\circ} 42^{\prime} \mathrm{N}, 103^{\circ} 51^{\prime}\right.$ E), Wenjiang, China. The seeds of Chinese cabbage named quick 35 were harvested in 2014 and purchased from Chengdu, China. All chemicals used in experiments were of analytical grade. Melatonin was purchased from Sigma-Aldrich (St. Louis, MO, USA).

Experimental Design. Seeds were sterilized in 10\% sodium phosphate solution for 30 minutes, flushed five times in distilled water, and then placed on 9-cm-diameter Petri dishes with three layers of filter paper moistened with distilled water and germinated at $25^{\circ} \mathrm{C}$ in darkness. Seeds were considered germinated when the seed coat was broken and a radicle was visible. After germination, 
seeds were planted in nutrition pot filled with vermiculite and perlite, the pot was ten centimeters in diameter and height.

Seedlings were irrigated with $20 \mathrm{ml}$ Hoagland nutrient solution containing $50 \mu \mathrm{mol} \cdot \mathrm{L}^{-1}$ concentrations of aluminum every other day, until the experiment finishing.

When the third leaf expanded, their leaves were sprayed with $0(\mathrm{CK}), 50,100,200,400 \mu \mathrm{mol} \cdot \mathrm{L}^{-1}$ concentrations of melatonin solution until foliage and dorsal dripping. Seedlings were sprayed with melatonin solution every other day, and three times in total. Each treatment consisted of 10 pots with one plant per pot. Positions of the pots were randomly changed daily to minimize positional effects. 30 days after treatment, the photosynthesis of each plant was determined by using LI-6400 portable photosynthesis meter (LI-COR Inc., USA). The photosynthetic parameters of the photosynthesis meter were manual control $\mathrm{CO}_{2}$ concentration $400 \mu \mathrm{mol} \cdot \mathrm{CO}_{2} \mathrm{~mol}^{-1}$, temperature $25^{\circ} \mathrm{C}$, light intensity $1200 \mu \mathrm{mol} \mathrm{m}{ }^{-2} \cdot \mathrm{s}^{-1}$. The determination of photosynthetic parameters were net photosynthetic rate $(\mathrm{Pn})$, transpiration rate $(\mathrm{Tr})$, stomatal conductance $(\mathrm{Gs})$ and $\mathrm{CO}_{2}$ concentration of intercellular $(\mathrm{Ci})$, and each treatment was repeated three times. Water use efficiency $($ WUE $)=$ net photosynthetic rate $(\mathrm{Pn}) /$ transpiration rate (Tr), Light use efficiency $(\mathrm{LUE})=$ net photosynthetic rate $(\mathrm{Pn}) /$ light intensity[13]. Statistic analyses. Statistical analyses were performed using SPSS 13.0 statistical software (IBM, Chicago, IL, USA). Data were analyzed by one-way ANOVA with least significant difference (LSD) at a $5 \%$ confidence level.

\section{Results and Discussion}

Net Photosynthetic Rate (Pn). Compared with CK, melatonin enhanced Pn of Chinese cabbage under Al stress significantly, and the Pn of Chinese cabbage was increased with the increasing of MT concentration from $50 \mu \mathrm{mol} \cdot \mathrm{L}^{-1}$ up to $200 \mu \mathrm{mol} \cdot \mathrm{L}^{-1}$ (Fig. 1). When the concentration of MT were 50, 100 and $400 \mu \mathrm{mol} \cdot \mathrm{L}^{-1}$, these treatments enhanced Pn of Chinese cabbage by $20.49 \%(p>0.05), 32.30 \%$ $(p<0.05)$ and $28.64 \%(p>0.05)$ respectively, compared with CK. When the concentration of MT was $200 \mu \mathrm{mol} \cdot \mathrm{L}^{-1}$, Pn of Chinese cabbage reached the highest, and increased by $63.22 \%(p<0.05)$. In this study, it was illustrated that melatonin can alleviate the Al stress and improving photosynthetic capacity of Chinese cabbage seedlings.

Transpiration Rate (Tr). Compared with CK, melatonin increased the Tr of Chinese cabbage with the increasing of MT concentration (Fig. 2). The trend of Tr was consistent with Pn. Compared with $\mathrm{CK}$, when the concentration of MT was $200 \mu \mathrm{mol} \cdot \mathrm{L}^{-1}$, Tr of Chinese cabbage reached the highest, and increased by $41.25 \%(p<0.05)$. It was showed that melatonin can alleviate the Al stress of Chinese cabbage seedlings.

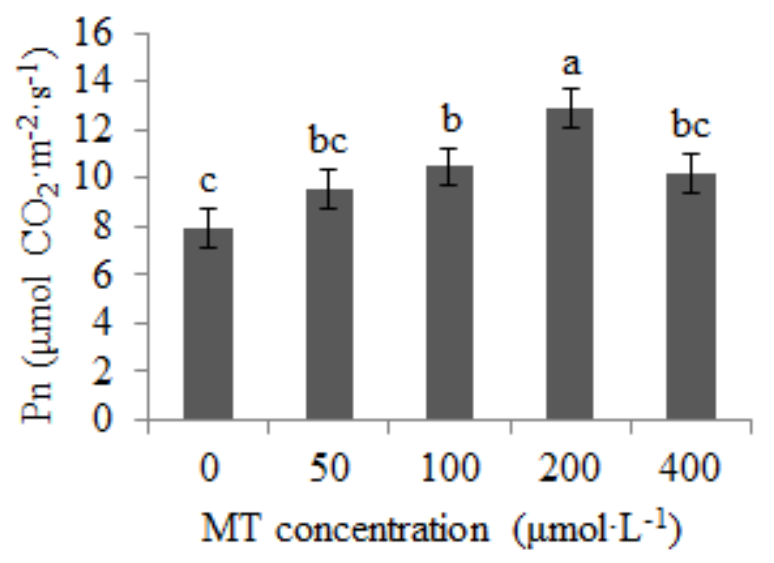

Fig. 1 Pn of MT sprayed Chinese cabbage

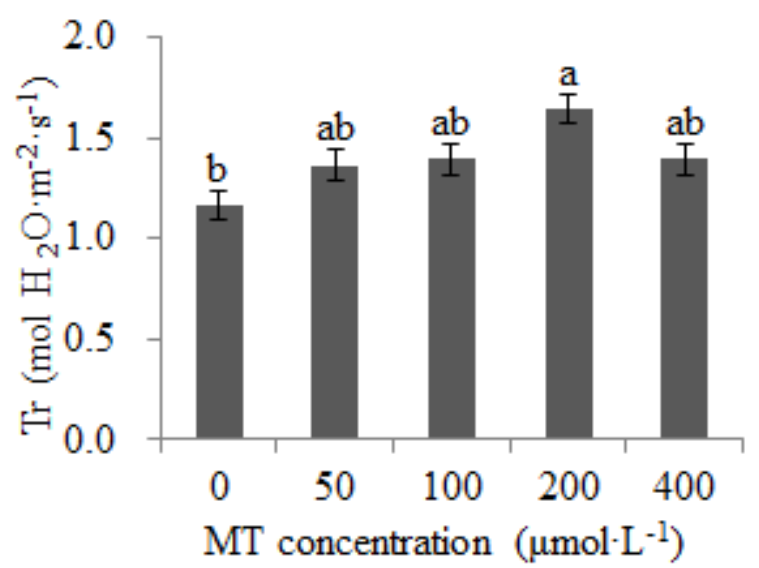

Fig. 2 Tr of MT sprayed Chinese cabbage 
Water Use Efficiency (WUE). The Fig. 3 shows that WUE of Chinese cabbage increased by melatonin treatment under Al stress. Compared with CK, when the concentration of MT were 50, 100, 200 and $400 \mu \mathrm{mol} \cdot \mathrm{L}^{-1}$, these treatments increased WUE of Chinese cabbage by $2.83 \%(p>0.05)$, $10.39 \%(p>0.05), 15.56 \%(p<0.05)$ and $7.40 \%(p>0.05)$, respectively.

Light Use Efficiency (LUE). Melatonin increased the LUE of Chinese cabbage with the increasing of MT concentration under Al stress (Fig. 4). When the concentration of MT were 50, 100 and 400 $\mu \mathrm{mol} \cdot \mathrm{L}^{-1}$, these treatments enhanced LUE of Chinese cabbage by $20.49 \%(p>0.05), 32.30 \%(p>0.05)$ and $28.64 \%(p<0.05)$ respectively, compared with CK. When the concentration of MT was 200 $\mu \mathrm{mol} \cdot \mathrm{L}^{-1}$, LUE of Chinese cabbage reached the highest, and increased by $63.22 \%(p<0.05)$. It was showed that melatonin can alleviate the Al stress of Chinese cabbage seedlings.

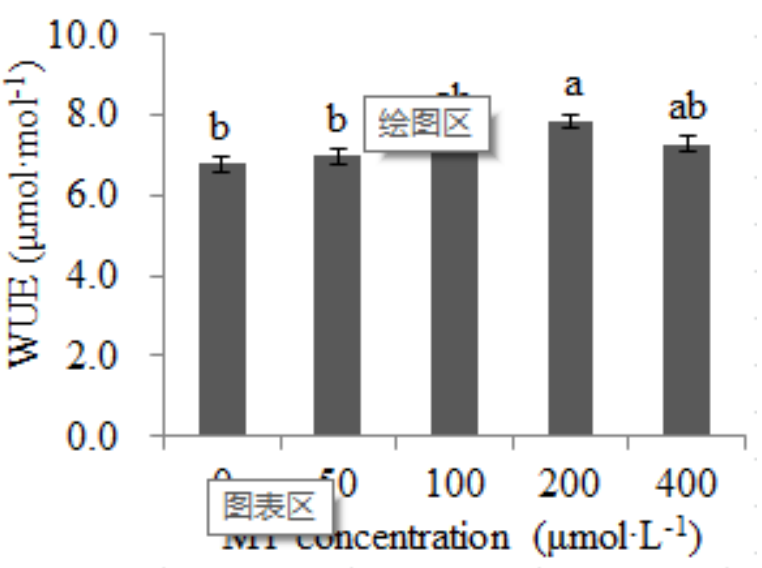

Fig. 3 WUE of MT sprayed Chinese cabbage

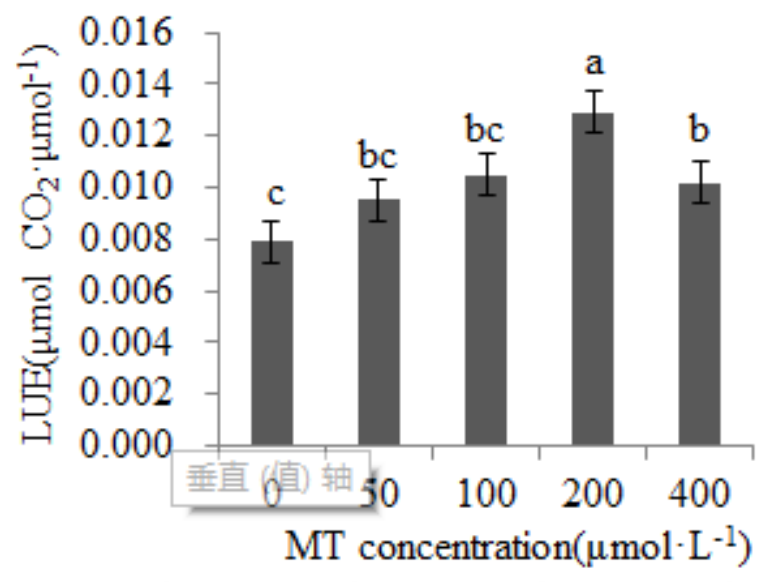

Fig. 4 LUE of MT sprayed Chinese cabbage

Stomatal Conductance (Gs). After spraying melatonin, Gs of Chinese cabbage increased (Fig. 5). The Gs of Chinese cabbage was increased with the increasing of MT concentration from $50 \mu \mathrm{mol} \cdot \mathrm{L}^{-1}$ up to $200 \mu \mathrm{mol} \cdot \mathrm{L}^{-1}$. Gs of Chinese cabbage reached the highest, and increased by $61.01 \%(p<0.05)$. $\mathrm{CO}_{2}$ Concentration of Intercellular (Ci). Treatments of different concentrations of melatonin were not significant. Compared with CK, the difference between all treatments didn't appear obviously, which illustrate that the impact of melatonin on $\mathrm{Ci}$ was not obvious.

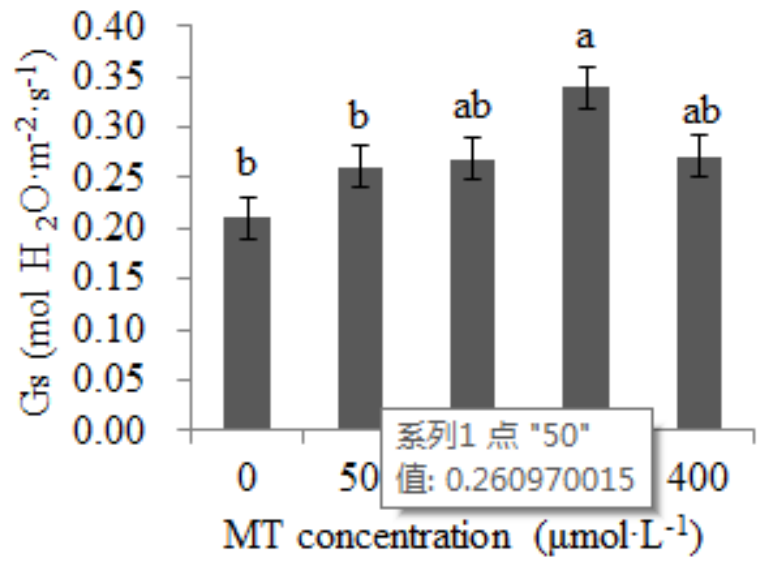

Fig. 5 Gs of MT sprayed Chinese cabbage

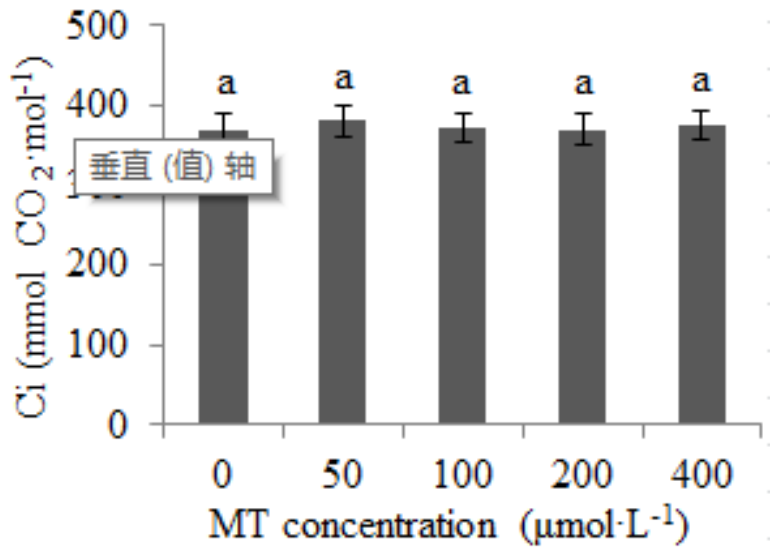

Fig. 6 Ci of MT sprayed Chinese cabbage 


\section{Conclusions}

Melatonin can alleviate the Al stress on photosynthetic organ damage and improving photosynthetic capacity of Chinese cabbage seedlings. With the increasing of MT concentration, $\mathrm{Pn}$ and $\operatorname{Tr}$ of Chinese cabbage were enhanced significantly. The result of LUE, WUE and Gs were the same as Pn. Spraying different concentrations of melatonin on Chinese cabbage under aluminum stress has not significant effect on $\mathrm{Ci}$. Therefore, melatonin could use to enhance the photosynthetic ability of Chinese cabbage, which would help to improve the adaptability of Chinese cabbage.

\section{Acknowledgements}

This work was financially supported by the Sichuan Agricultural University "Shuang-Zhi Plan" Foundation.

\section{References}

[1] M.H. Zhao and J.L. Zhao: Shanxi Journal of Agricultural Sciences Vol. 42 (2014), p.1071-1074 (In Chinese).

[2] J.H. Weng, L.F. Huang and X.R. Liu: China Environmental Science Vol. 20 (2000), p.501-505 (In Chinese).

[3] X.F. Ying and P. Liu: Chinese Journal of Applied Ecology Vol. 16 (2005), p.166-170 (In Chinese).

[4] X.X. Xiao, X.H. Liu and Z.W. Yang: Chinese Journal of Tropical Crops Vol. 26 (2005), p.63-69 (In Chinese).

[5] S.Y. Yan and Y. P. Wang: Guangdong Journal of Agricultural Sciences Vol. 40 (2013), p.16-20 (In Chinese).

[6] T.T. Jin and P. Liu: Chinese Journal of Oil Crop Sciences Vol. 28 (2006), p.302-308 (In Chinese).

[7] Q.X. Li and X.L. Tang: Guangxi Agricultural Sciences Vol. 37 (2006), p.249-252 (In Chinese).

[8] P. Wang and Q. Chen: Soybean Science Vol. 32 (2013), p.650-654 (In Chinese).

[9] Y. Zhao and D.H. Wang: Acta Botanica Boreali-Occidentalia Sinica Vol. 34 (2014), p.196-205 (In Chinese).

[10] G.Y. Zhang and W.H. Liu: Chinese Traditional and Herbal Drugs Vol. 34 (2003), p.87-89 (In Chinese).

[11] T. Iskender, K. Huseyin: Journal of Pineal Research Vol. 52 (2012), p.332-339

[12] X. Y. Lei andR. Y.Zhu: Journal of Pineal Research Vol. 36 (2004), p.126-131

[13] X.J. Jiang, H. Wang and W. Peng: Shanxi Journal of Agricultural Sciences Vol. 54 (2008), p.56-58 (In Chinese). 